\title{
Mundos alternativos. Creatividad y surrealismo en los libros de artista de Moisès Villèlia*
}

\author{
Moisés Bazán de Huerta \\ Universidad de Extremadura \\ mbazan@unex.es
}

RESUMEN: Moisès Villèlia (Barcelona, 1928-1994) es uno de los artistas más originales de la vanguardia española, aunque su trayectoria no ha sido suficientemente reconocida. Como escultor incorporó nuevos materiales, destacando sus livianas creaciones en caña de bambú. Con este medio realizó móviles y esculturas abstractas de personalidad inconfundible.

Pero a su obra escultórica hay que añadir su pasión por la escritura y su labor como dibujante e ilustrador. La unión de estas facetas generó varios libros de artista; algunos fueron editados y otros permanecieron inéditos. Este artículo aporta y analiza seis proyectos, casi todos desconocidos: Estado de cuentas, Los engranajes, El diluvio universal, El bambú y la luna, Fisuras en el espejo y La unidad de los conjuntos. Fueron concebidos en Cabrils, París, Quito y Molló entre los años sesenta y ochenta. En ellos Villèlia combina imágenes y textos, algunos en clave surrealista, con temas y estilos muy versátiles.

PALABRAS CLAVE: Moisès Villèlia; Escultura; Libro de artista; Libro ilustrado; Dibujo; Texto e imagen.

\section{Alternative Worlds. Creativity and Surrealism in Moisès Villèlia's Artist Books}

ABSTRACT: Moisès Villèlia (Barcelona, 1928-1994) is one of the most original artists of the Spanish avant-garde, although his career has not been sufficiently recognized. As a sculptor he incorporated new materials, featuring light creations in bamboo cane. By using this material he made mobiles and abstract sculptures of unmistakable personality.

But we must add his passion for writing and his works produced as a draftsman and illustrator to his sculptural work. The union of these facets generated several artist's books; some were printed and others remained unpublished. This article brings to light and analyses six projects, almost all of them unknown: Estado de cuentas, Los engranajes, El diluvio universal, El bambú y la luna, Fisuras en el espejo and La unidad de los conjuntos. They were conceived in Cabrils, Paris, Quito and Molló between the 1960s and 1980s. In them Villèlia combines images and texts, some in a surrealist key, with very versatile themes and styles.

KEYWORDS: Moisès Villèlia; Sculpture; Artist Book; Illustrated Book; Drawing; Text and Image.

Recibido: 20 de enero de 2021 / Aceptado: 5 de mayo de 2021.

Moisès Villèlia (Barcelona, 1928-1994) [1] es uno de los escultores más originales de la vanguardia española en la segunda mitad del siglo XX. Su trayectoria no ha sido suficientemente valorada, a pesar de contar con una importante monografía (Borràs, 1974) y exposiciones antológicas en la Fundación Miró (1983) y el IVAM (1999), junto a numerosos textos en catálogos de exposiciones y artículos críticos en revistas ${ }^{1}$. Al proceso de recuperación de su figura que se ha producido en el presente siglo a través de estudios y galerías, sumamos esta aportación inédita.

Se forma inicialmente como tallista, pero evoluciona de manera autodidacta con un talento innato hasta descubrir nuevos modos de expresión. Materiales humildes, con los que se adelanta al arte povera, series como «Tela de araña», con

Cómo citar este artículo: BAZÁN DE HUERTA, Moisés, "Mundos alternativos. Creatividad y surrealismo en los libros de artista de Moisès Villèlia", Boletín de Arte-UMA, n. ${ }^{\circ}$ 42, Departamento de Historia del Arte, Universidad de Málaga, 2021, pp. 225-236, ISSN: 0211-8483, e-ISSN: 2695-415X, DOI: http://dx.doi.org/10.24310/BoLArte.2021. vi42.11591 


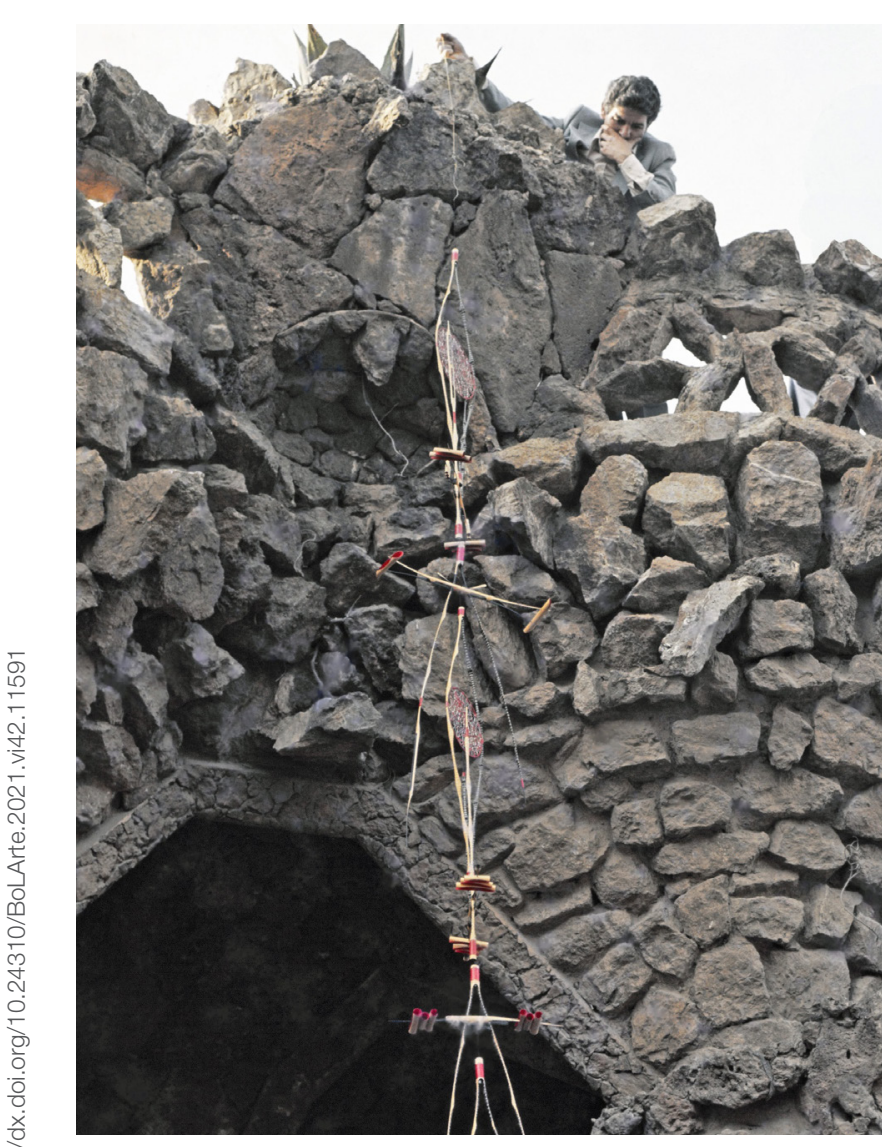

1. Moisès Villèlia montando un móvil en el Parc Güell. Barcelona, 1973 alambres e hilos lacados, o el posterior uso del fibrocemento le abren insólitos horizontes; pero será la caña de bambú el elemento que le otorgue una mayor proyección y especificidad en el panorama artístico. Es un material en principio poco apto para la escultura, pero que en sus manos asume un enorme cúmulo de posibilidades. En paralelo a lo que Manuel Rivera haría con la tela metálica o Manolo Millares con la arpillera ${ }^{2}$, Villèlia encarna esa nómina de creadores con personalidad indiscutible por haber aportado un nuevo material a la experiencia artística.

Su capacidad para sacar partido al bambú parece infinita. Lo talla, secciona, perfora, curva, le aplica zonas de color y conecta unas piezas con otras para lograr un equilibrio y elegancia sorprendentes, sobre todo en sus livianos móviles, que ofrecen una alternativa genuina a las opciones aportadas por Alexander Calder o Ángel Ferrant ${ }^{3}$. Su obra ha sido asociada al constructivismo de Gabo, al que admiraba, pero la entendemos próxima a propuestas organicistas del propio Ferrant, Leandre Cristófol o Adolfo Schlosser.

En su trayectoria vital hay varios puntos de inflexión [2]. Tras una primera etapa catalana en Barcelona, Mataró y Cabrils, en 1967 y 1968 estuvo en París, más dedicado al dibujo, proyectos y el diseño de jardines por la falta de espacio para ejercer la escultura. Entre 1970 y 1972 residió en Argentina y Ecuador, donde consigue bambúes de mayor

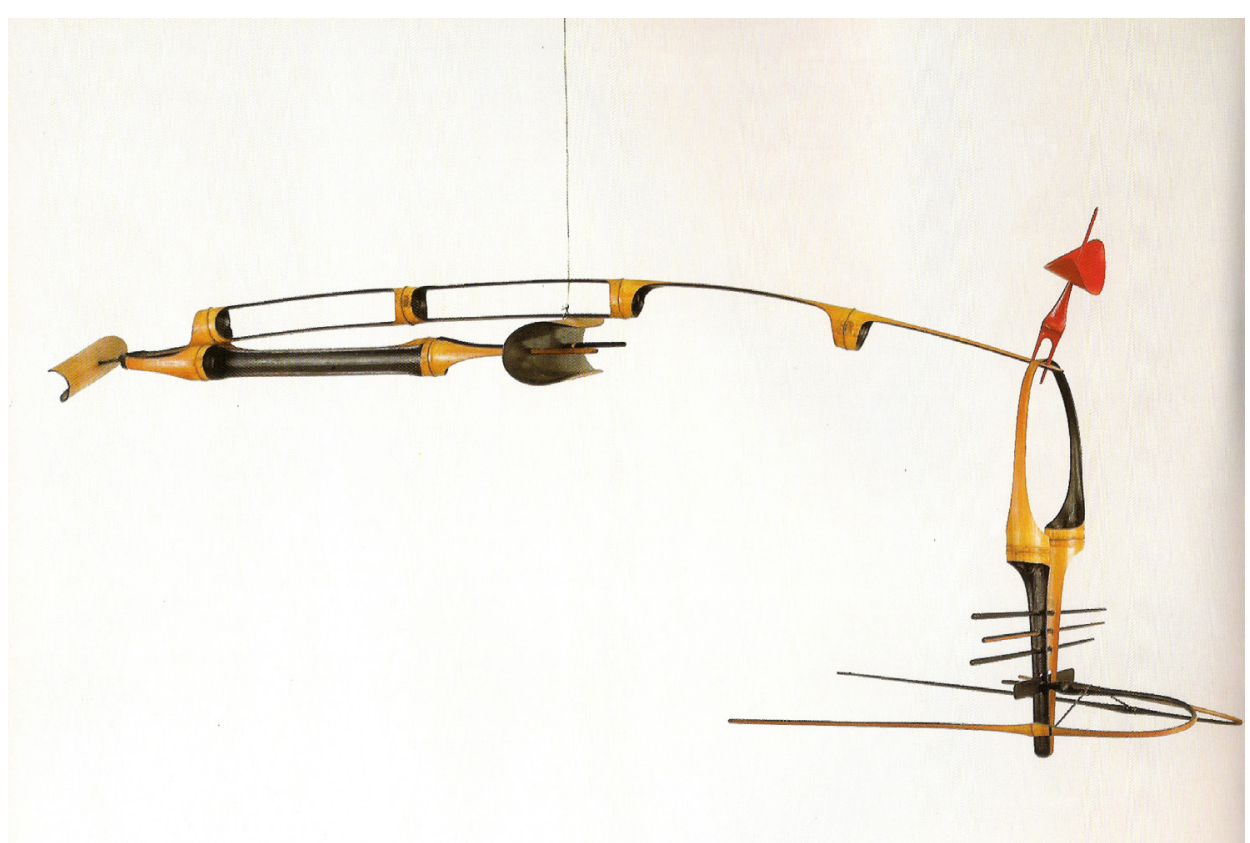

2. Móvil de Moisès Villèlia en caña de bambú. Molló, 1980 
3. Lámina de Las Cañas, libro editado por la Sala Gaspar, 1974

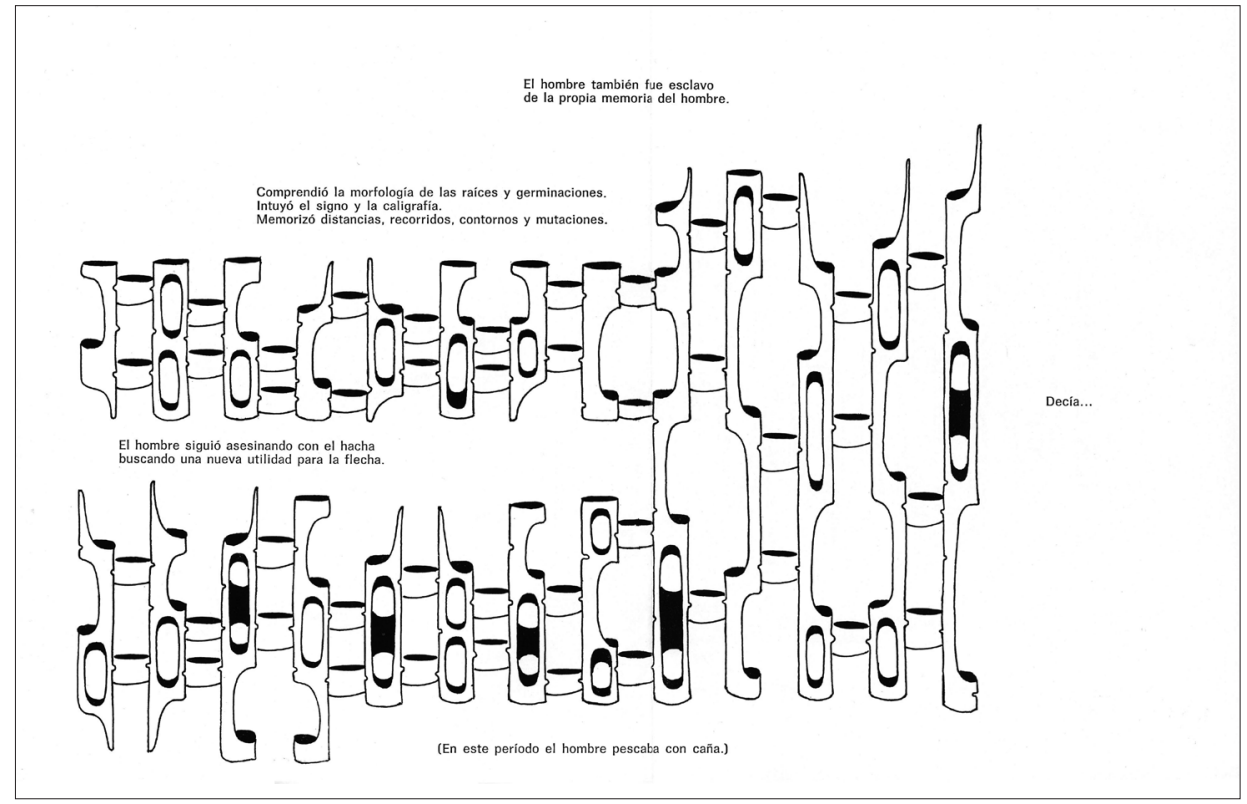

tamaño y grosor. A su regreso se instala finalmente en Molló (Gerona) y construye una amplia casa-estudio en plena naturaleza.

En los años sesenta, a instancias de Joan Prats y Alexandre Cirici, pasaron por su estudio importantes artistas, críticos y directores de museos internacionales: Joan Miró, Antoni Tàpies, Joan Ponç, Pierre Matisse, Michel Tapié, Udo Kultermann, Walter Holzhanserm, James Johnson Sweeney o Frank O'Hara, admirándose de su falta de precedentes y cómo los elementos de Villèlia les sugerían las más diversas evocaciones sin que el artista representara miméticamente ninguna de ellas (Cirici, 1982). Aun así, quizás no supo o no quiso aprovechar del todo estas posibilidades, al mantener cierto distanciamiento de los círculos artísticos oficiales y declinar por ejemplo representar a España en la Bienal de Sao Paulo de 1968 (Bufill, 2005). En cualquier caso, su obra está representada en grandes museos españoles de arte contemporáneo, como el Reina Sofía de Madrid, el MACBA y la Fundació Joan Miró de Barcelona, el Patio Herreriano de Valladolid o el IVAM de Valencia.

Aunque está más acreditado como escultor, Villèlia también colaboró con arquitectos y diseñó jardines, muebles, juegos y escenografías. Y dibujó, dibujó siempre y con distintos fines; ya fuera como boceto o ensayo para ideas tridimensionales o a la inversa, a modo de firma, pues acom- pañaba sus esculturas con un diseño como garantía de autenticidad y guía para su correcto montaje (Subirana, 1976). Pero también el dibujo fue un medio propio, independiente, que dio lugar a interminables series, en buena medida inéditas y actualmente en fase de estudio ${ }^{4}$.

Sus trabajos sobre papel le llevaron así a concebir libros de artista, que ampliaban el marco de su universo creativo, no limitándose al uso de la línea, sino sumando el color, el collage o la perforación. En este sentido, mantuvo relación con representantes clave de la poesía visual española, como Joan Brossa. Sus primeros resultados son colaborativos. En 1962 el Club 49 editaba el Libro de linòleums con texto de Josep Rabasseda, y participó con la caja y una pieza escultórica en la edición de Cop de Poma, junto a Joan Brossa, Josep Maria Mestres Quadreny, Joan Miró y Antoni Tàpies. En colaboración con Brossa realizó en 1973 La cabaleta, publicado por Polígrafa y Cartipàs por la Sala Gaspar (para el que Brossa sugirió 146 títulos alternativos). En ambos utilizó el troquelado como medio expresivo.

Combinando dibujo y texto, en Quito editó en 1971 la Suite Las Cañas, ideada en París cuatro años antes; y con parámetros similares la Sala Gaspar publicó en 1974 Las Cañas [3], un libro muy completo que reflexiona sobre el material y complementaba sus exposiciones (Subirana, 1976). También en la web del artista se puede consultar $A$ 

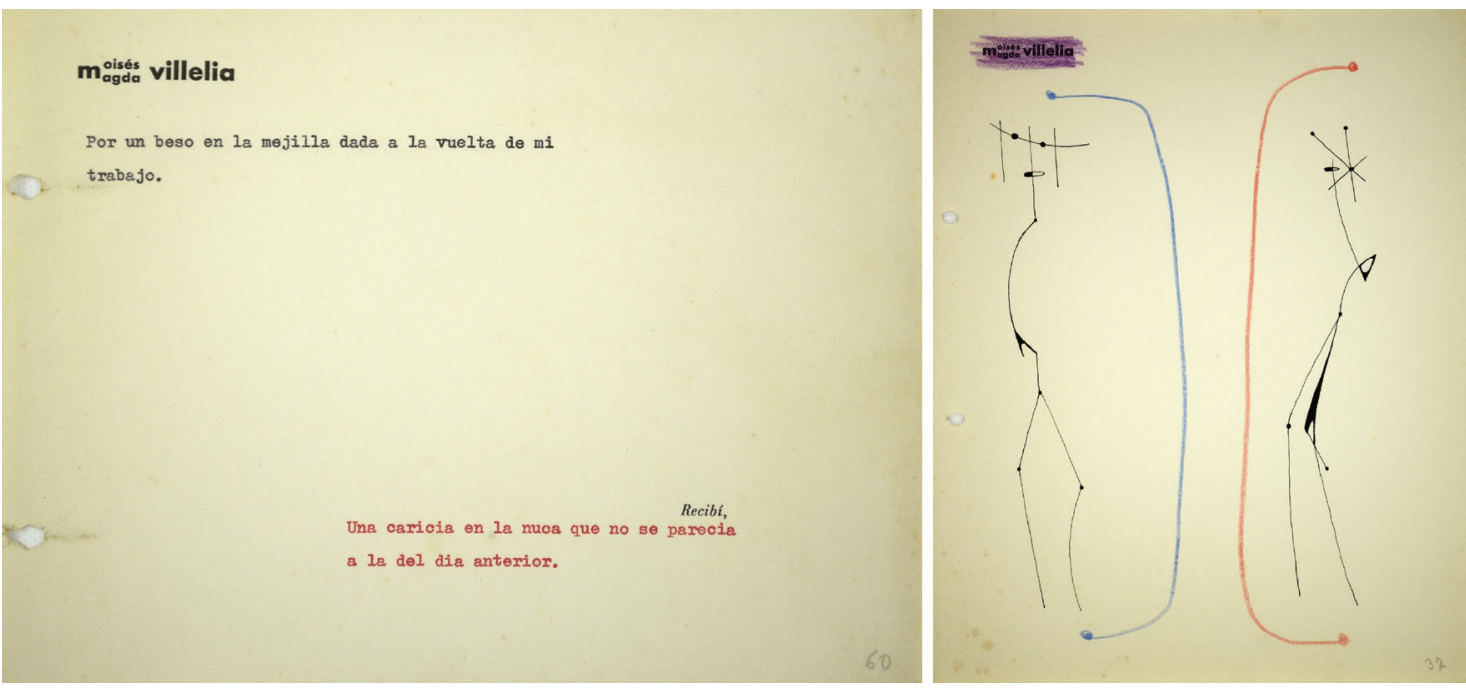

4. Estado de cuentas. Cabrils, 1967

Mataró, de 1975. En los tres el texto es tan importante como la imagen y ambos se integran o alternan en las hojas.

Y es que Moisès Villèlia cultivó también la escritura y la poesía, con tintes próximos al surrealismo; de hecho, en sus inicios se planteó seguir una vocación literaria que siempre mantuvo. Fusionar ambas facetas encontraba en los libros un aliciente tentador y es el que nos proponemos recuperar, por cuanto su obra escultórica es más conocida. Sobre los proyectos ilustrados de Villèlia se han publicado escasas aproximaciones, destacando algunas citas de María Lluïsa Borràs (Borràs, 1974 y 1999) y un texto de su hijo Nahum (Villèlia, 1999: 107-113).

La difícil salida y rentabilidad de estos trabajos y las prioridades de la Sala Gaspar con la que Villèlia trabajaba imposibilitaron publicar un buen número de proyectos concebidos también por el autor como libros de artista y que ofrecen el mismo o mayor interés que los citados. Conviene matizar que no todos se entendieron como objeto intervenido, sino que podrían encajar en el concepto de libro ilustrado, susceptible de editarse en un formato más o menos tradicional. De los seis que presentamos solo uno vería la luz, y a posteriori; los demás permanecen inéditos. Hemos optado por una selección muy variada y dilatada en el tiempo, en aras de mostrar la versatilidad del artista.

La propuesta más temprana surge desde el ámbito más íntimo. Estado de cuentas [4] fue elaborado y compi- lado en Cabrils en 1967, antes de la marcha del escultor a París. Consta de 20 textos y 40 láminas a tinta y lápiz sobre papel, más la cubierta con el título. Números romanos de factura sencilla van presentando cada doble idea, compuesta por un dibujo y un pasaje escrito.

Los dibujos siguen una estética peculiar, conectada con una serie previa firmada en 1962 y algunos personajes de 1966. Evocan formalmente recursos mironianos, apuntando su componente surrealista, o bocetos realizados por Picasso en el contexto de las constelaciones y el proyecto monumental a Guillaume Apollinaire, donde las intersecciones lineales se remarcan con puntos (Lichtenstern, 1996: 42-65). Al tiempo participan de una estética filiforme compartida por artistas como Giacometti, Calder o Ferrant, y ejemplificada en otras series del autor como Los hombres en calidad de alambre. Su factura es muy estilizada. Líneas mínimas sintetizan el torso y las extremidades, y en la cabeza se adivinan supuestos tocados, signos o proyecciones astrales. Son en realidad dos personajes que se relacionan: se abrazan, unen sus manos o comparten elementos, envueltos por líneas coloreadas abarcantes. Pero también en otros diseños se distancian, separados por trazos de color en direcciones opuestas. $Y$ es que actúan como un trasunto de las relaciones de pareja, y en ello van acordes con los textos que complementan el proyecto.

Estos son también muy singulares. Usan como soporte hojas impresas por el matrimonio, que en el membrete 
utilizan una M común para los nombres de Moisès y Magda, compartiendo el apellido Villèlia. Con todo, los textos y dibujos son exclusivos de Moisès. Habían elaborado estos recibos en una época de frecuente trato con arquitectos y clientes. En el espacio reservado para el concepto se reseña una determinada tarea o situación; y bajo el recibí, donde debería ir la firma, se desarrolla con tinta roja una respuesta o recompensa a la acción apuntada. Se crea así un esquema repetido que va narrando hechos cotidianos y desvela un cúmulo de circunstancias tan reconocibles como imaginativas. Se entenderá mejor al valorar algunos ejemplos:

«Por una conversación sostenida en la cama sobre las 7 o 8 de la mañana, recibí una taza de café sin una sola gota derramada en el plato».

«Para hacer comprender que el día en que nos conocimos era un día como otro cualquiera, recibí la lectura del más reciente poema de Brossa".

«Por consolar al niño que estaba llorando y tú estabas nerviosa, recibí una historia contada al niño que me hubiera gustado inventarla yo».

«Por un beso en la mejilla dado a la vuelta de mi trabajo, recibí una caricia en la nuca que no se parecía a la del día anterior».

En definitiva, estamos ante un intercambio, un estado de cuentas de consumo interno que revela todo un trasfondo personal y familiar. Por ello, y por su factura, no es un trabajo dirigido a ser impreso, sino un regalo del artista a su esposa destinado a permanecer en el ámbito de lo privado, aunque no por ello resulte menos sugestivo.

El siguiente proyecto sí surge con vocación editorial, ahora a partir de la lectura de una obra ajena. Los engranajes [5] es el último relato del escritor japonés Ryunosuke Akutagawa (Tokio, 1892-1927), especializado en el cuento corto. El atormentado autor se suicidaría poco después de su conclusión. De hecho, el premonitorio texto termina así: «Fue la experiencia más aterradora de mi vida... ya no tengo fuerzas para seguir escribiendo. Es inexpresablemente doloroso vivir en este estado mental ¿No hay nadie que venga y me estrangule en silencio mientras duermo?»

El proyecto de Villèlia se elaboró en mayo de 1968, en paralelo a otras interesantes series, pues su estancia en la capital francesa fue una época de intenso trabajo en los
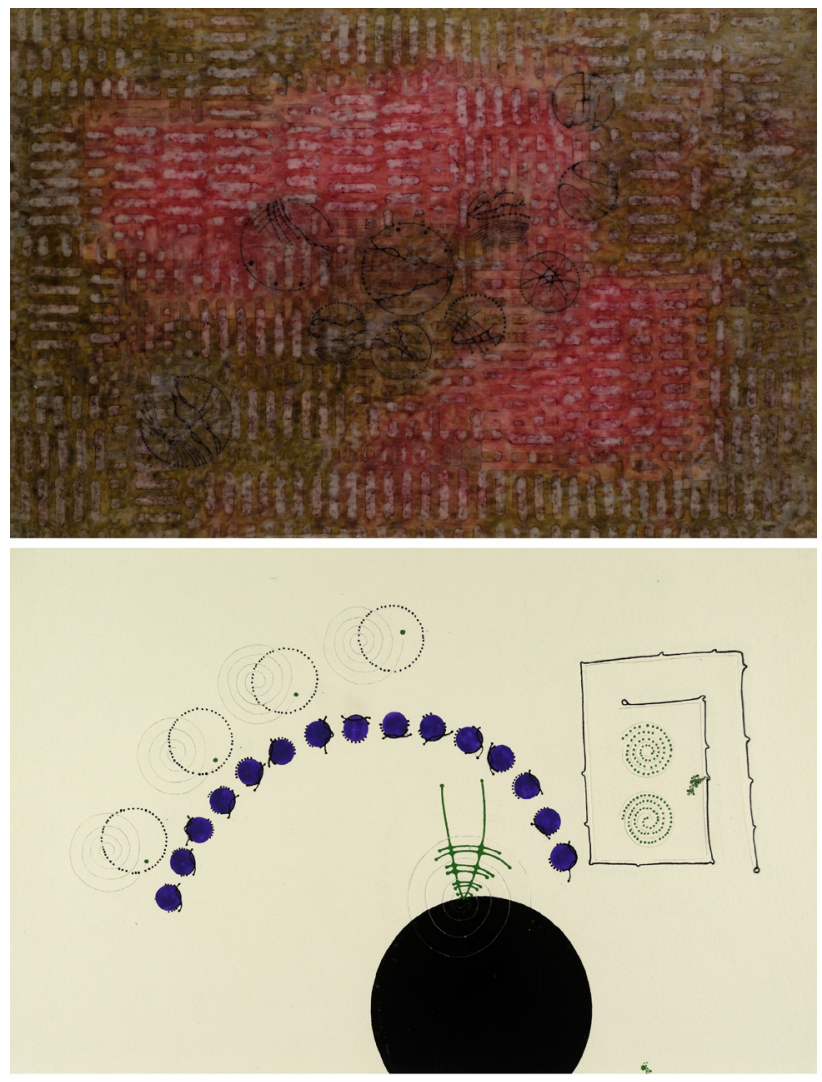

5. Los engranajes. Cubierta y lámina. París, 1968

ámbitos del dibujo y la literatura. El mismo autor cuenta en la introducción al libro su proceso creativo:

En mayo de 1968 me encontraba en París. Me encontraba en París, pero no me encontraba a mí mismo. Este divorcio era compensado al ver la cantidad de idiotas sueltos que encontraban menos que yo. La condición de extranjero predisponía prudencia y también aislamiento, cosa que practicaba. En esta solitud cayó en mis manos el último relato que escribiera Akutagawa, Los engranajes. El relato describe el estado de ánimo de un suicida. La apatía constante que motiva el distanciamiento progresivo de todo lo que fueran motivaciones.

El personaje es consciente de ello. Cuando intenta racionalizar, solamente concibe unos engranajes perfectamente funcionando sin pasado ni futuro, como si a un reloj digital le hubiesen puesto la maquinaria de uno deductivo. Sería una locura. Algo parecido le sucedió a Akutagawa. 
El relato me impresionó. Yo me consideraba propicio para el suicidio. Estaba intoxicado de esta anécdota y de la misma manera que cualquier japonés es propenso de llegar al Satori, cabalgando sobre la espiral de un Koan. No estaba en lo cierto. Yo no era ningún suicida y Akutagawa que era japonés estaba chalado y bien chalado. Sus relatos me habían emocionado por su fluidez mental más que por sus anécdotas narrativas.

Me puse a pensar en espirales en aquel idiotizado mayo parisino. Me dolía que Akutagawa no hiciera lo mismo ante sus engranajes. Me dolía que una persona tan sutil para comprender los recorridos de la memoria se olvidase de las espirales. Me puse a dibujarlas para ofrecérselos como homenaje a su memoria. Cuentan de un árbol que reciclaron a celulosa y todo lo que quedó de él fue un libro de lectura pedante y hojas secas entre sus páginas. Lo mismo deseo de mis dibujos. Sean como hojas secas que se pierden entre los engranajes de mi estimado Ryunosuke Akutagawa.

Estos párrafos muestran la coherencia de Villèlia al plasmar sus sensaciones y aportan las claves para comprender las imágenes. En efecto, las ilustraciones se centran en la espiral como motivo artístico, aunque reproduce al tiempo esquemas rectilíneos a modo de laberintos unidireccionales, y ambos se combinan con círculos, superponiendo formas y colores además de incisiones con cúter. El resultado es unitario sin resultar monótono, pues hay soluciones plásticas muy distintas. Es una abstracción rica y sugerente, en la que los motivos destacan ante el blanco del papel, pero también se alternan con evanescentes fondos acuarelados. Las 44 hojas, de $31,5 \times 50 \mathrm{~cm}$, se completaban con unas originales cubiertas de poliestireno, troqueladas y revestidas por papel encolado; este se configuró a partir de plantillas de arquitecto y aplicando goma laca para crear efectos de transparencia muy interesantes. A este fondo geométrico Villèlia superpuso nuevos dibujos de espirales, si bien difíciles de percibir por la densidad de la trama.

Lo especifico y heterogéneo de la propuesta no hizo viable su publicación inmediata y no sería hasta 1992, en un período con mayores opciones de mercado, cuando el proyecto se vería finalmente culminado por iniciativa del empresario Manuel Viñas con el taller calcográfico de Tristan Barbarà. Así, Edicions Tristan presentó el libro de artista en una caja de madera, conteniendo la reproducción en pa- pel del estuche originario y 44 aguafuertes sobre Velin Arches, elaborados según métodos tradicionales. Fueron 36 libros numerados y 5 para los colaboradores, más una edición gráfica selectiva de 25 ejemplares sobre papel Aquari, con mayores márgenes, firmados y numerados por el autor. Villèlia, ya enfermo de cáncer, no pudo controlar la edición y asumió el resultado, aunque no estuviera muy de acuerdo con el mismo, pues se modificaron fondos y colores, además de suprimirse las zonas incisas.

La siguiente serie, que podemos agrupar como Los cromosomas [6], tiene también conexión con la estancia parisina. Ahora recuperamos el componente figurativo, pero tiene un origen singular y refleja los curiosos cauces que pueden inspirar a un artista. Deriva de la amistad de Villèlia primero en Barcelona con el hematólogo Dr. Viñas y en 1969 con el médico e investigador Jean Dausset (1916-2009), quien hizo brillantes aportaciones al estudio de la hematología, los trasplantes y la genética, que le reportarían el Premio Nobel de Medicina en 1980. Dausset compartió con Villèlia imágenes microscópicas y experimentos, relacionados entre otros temas con los cromosomas, que transmiten el material genético determinando el género.

Estos contactos estimulan la imaginación del artista para crear un universo plástico muy original. Surgen así Los cromosomas, a partir de la apariencia en $\mathrm{X}$ y con su evocación nominal, aunque adopten en la práctica formas independientes. Estos seres se desenvuelven en un entorno propio y acabarán asumiendo situaciones fantásticas y surreales, que justifican en gran medida la condición de mundos alternativos utilizada en el título de este trabajo. Los personajes se identifican con facilidad por estar dibujados con un solo trazo sin levantar el lápiz del papel, salvo en el pequeño espacio que permite situar un único ojo. Los masculinos son esencialmente una cabeza sobre dos piernas, mientras los femeninos, sin extremidades, portan una suerte de túnica.

Con estos protagonistas Villèlia desarrolló dos proyectos de libros de artista, bajo los títulos Los cromosomas y su paisaje (París, 1969) y Los cromosomas y su personalidad (Molló, 1973), en los que predomina el componente visual. El primero refleja, con trazos limpios aunque enigmáticos, un universo idílico y contemplativo en que los personajes viven en comunión con la naturaleza. El segundo, más ambicioso y disperso (87 láminas frente a las 47 de la primera serie), 

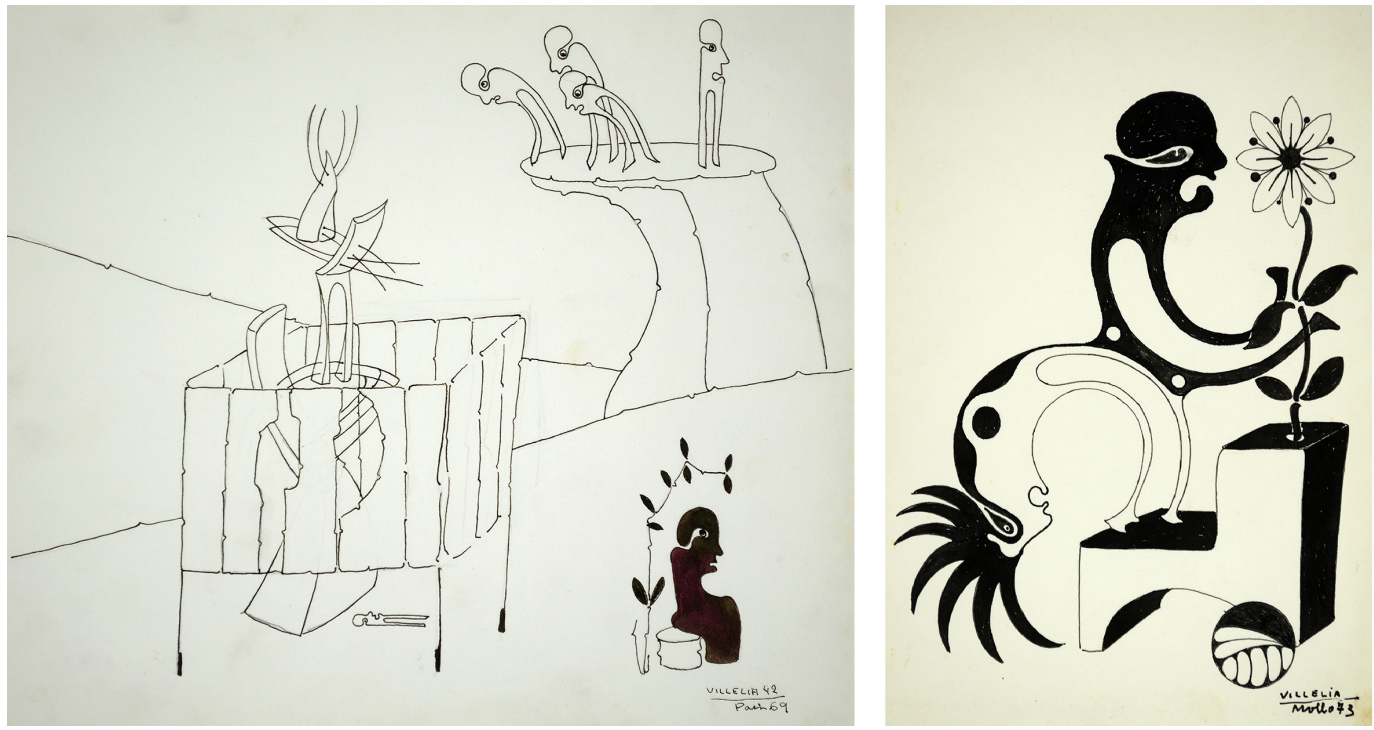

6. Los cromosomas y su paisaje. París, 1969. Los cromosomas y su personalidad. Molló, 1973

enriquece la iconografía de estos seres, metamorfoseándolos con objetos y elementos vegetales, animales o decorativos, además de incorporar textos que complementan su identificación o reflejan insólitas situaciones surrealistas. Nos hemos ocupado de ambos en un estudio paralelo, analizándolos junto a otra valiosa propuesta: Los personajes de Les Lilas, enmarcada, como Estado de cuentas, entre la cotidianeidad y el surrealismo, aunque su resolución plástica es bien distinta ${ }^{5}$.

Hemos citado sendos proyectos sobre Los cromosomas por su interés, y destacamos que en el primero Villèlia fijó ya la iconografía que, a modo de estilema plástico, seguirá desarrollando en adelante. Para incrementar este personal imaginario queremos centrarnos ahora en otros dos que, aunque no llevan el término cromosomas en el título, utilizan los mismos personajes. La primera propuesta es breve, pero mantiene por ello una gran coherencia. Son 11 láminas dibujadas a tinta sobre papel de 37,5 x $25 \mathrm{~cm}$, aunque hay dos cuadrangulares algo menores. Fueron concebidas durante su estancia en Quito a lo largo de 1970. Quizás la prolongada estación lluviosa de la capital ecuatoriana contribuyó a la elección temática, pues la serie está inspirada por El diluvio universal [7]. Es, con todo, un motivo suficientemente conocido y potente, con enormes posibilidades plásticas. Aunque aparece en otras culturas, como el Poema de Gilgamesh mesopotámico, Villèlia tomaría como referencia lo su- gerido por el relato bíblico en Génesis 6-9: el castigo divino por la maldad del hombre, inundando la tierra y otorgando la salvación solo a Noé y su familia, encargados de preservar parejas de animales de cada especie terrestre o aérea.

Villèlia interpreta el tema de manera muy libre, aunque entre sus precedentes iconográficos pudiera valorar obras medievales (González, 2011), la reconstrucción secuenciada de Miguel Ángel en la Sixtina o, más probablemente, las ilustraciones decimonónicas de Gustave Doré. Prescinde de las alusiones a Noé, y como animales tan solo aparecen peces dorados asiáticos, fusionados con las olas y que, en un giro imprevisto, no solo ocupan el mar, sino también pequeñas isletas. Los personajes de ambos sexos que ya conocemos protagonizan las escenas, adaptando su posición a distintas circunstancias (erguida, sedente, precipitándose al agua o intentando flotar), con esas bocas siempre abiertas cuya mueca parece aquí gritar o expresar temor. Pretenden sobrevivir subidos a montañas o árboles, pero también sobre estructuras edificadas, más sugestivas visualmente por cuanto su geometría aporta una extraña modernidad. Estas construcciones se perciben también sumergidas y actúan como burbujas temporales para la subsistencia, en una solución plástica inteligente.

El acusado contraste entre blancos y negros es el recurso visual más llamativo, junto a una patente acumulación 

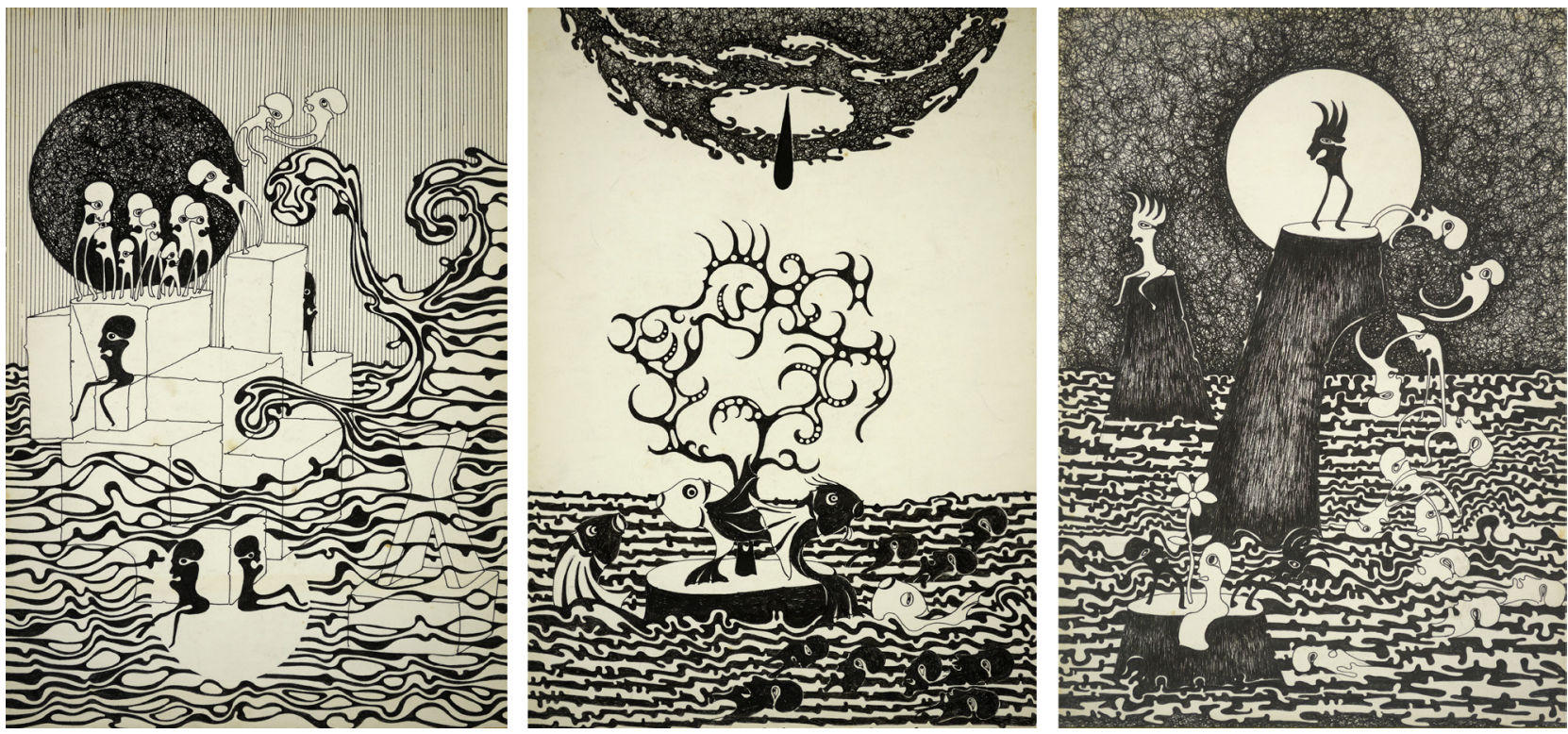

7. El diluvio universal. Quito, 1970

de elementos. El barroquismo domina las escenas, sin dejar apenas espacios libres, pues el entramado lineal afecta incluso a los fondos. Finas rayas verticales actúan como una cortina de lluvia, pero también hay bandas estratificadas y cielos borrascosos a partir de una densa maraña de trazos. En ocasiones estos se abren para dejar caer espesas gotas, mientras el mar se encrespa en sinuosas olas o asume una horizontalidad casi geométrica. Sin perder la identidad del conjunto, Villèlia combina una sorprendente variedad de opciones, en una recreación de marcado carácter esteticista. La limpieza y claridad de Los cromosomas y su paisaje se torna aquí contraste y tensión.

Villèlia daría continuidad a los cromosomas en casi un centenar de dibujos sueltos fechados en Molló entre 1978 y 1979, convirtiéndose así en una iconografía recurrente, que asumía continuas variantes. Pero estos trabajos no tenían vocación editorial, eran un escape para su infatigable necesidad de dibujar.

Hay que esperar a 1986 para localizar una nueva propuesta. Su singular estética reaparece así en El bambú y la luna [8], firmada también en Molló con idea de ser un pequeño libro ilustrado. Tres de sus dibujos han sido reproducidos (Villèlia, 1999: 112 y 2005: 47), si bien su estudio como serie permanece inédito.
Este proyecto editorial está compuesto por 13 láminas de 38 x $18 \mathrm{~cm}$, acompañadas por breves textos manuscritos. Recupera la uniformidad temática y estilística de El diluvio universal, que se había dispersado un tanto en Los cromosomas y su personalidad. El negro y el rojo marcan todas las planchas, reservando el segundo color (salvo en un caso) para la luna, compartimentada en fragmentos geométricos triangulares u ovalados.

El conjunto es muy coherente y nos interesa por ser el que reúne mayores referencias al universo escultórico del artista. Aunque su número sea reducido, asistimos a todo un despliegue de livianas cañas tensadas por travesaños y disposiciones abiertas o curvadas en forma de arco; vemos también móviles suspendidos por hilos y fragmentos tubulares seccionados que se enlazan por cordajes, al igual que en las obras tridimensionales del autor.

Estos elementos cobran en la composición tanta o más importancia que los personajes que comparten la escena. Aunque la coincidencia formal se mantiene, cabe entender que estos seres ya han perdido relación con los cromosomas de las primeras series. Tienen entidad propia y se han incorporado al acervo artístico del autor para colocarlos en las situaciones más diversas. Silueteados y rellenos en negro, ahora ostentan penachos o peinados di- 


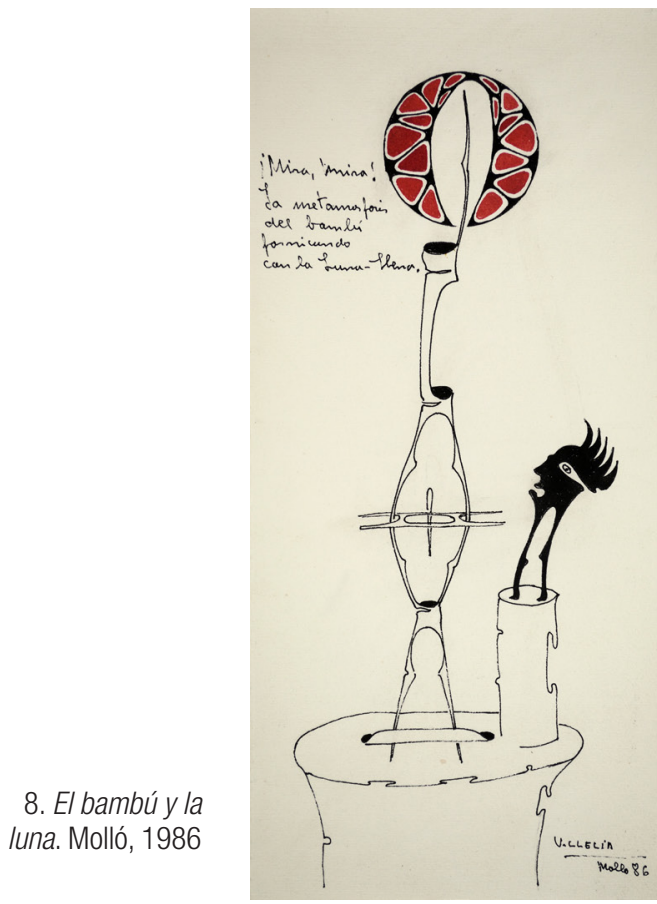

ferentes, y en su configuración hay tanto figuras masculinas como femeninas.

Desarrollan mínimas historias, algunas de contenido amoroso o sexual: «Pues es cierto. El bambú quiere abrazar a la luna»; «iMira, mira! La metamorfosis del bambú fornicando con la luna llena»; y hasta vemos a un supuesto Pierrot suicidándose por no poder soportar los amores de los bambúes con la luna. Otros textos inciden en el tema y se manifiestan en forma de diálogo: « ¿Te crees querida lo que dicen de los bambúes y de la luna?»; «iSí señora! Los guijarros-niños quieren ver lo que la luna hace a los bambúes»; o bien: «-Mira qué sonajero tiene la luna -No es un sonajero, es que se ha terminado la fiesta».

Las láminas restantes juegan con la ubicación de las figuras en plataformas y distintos soportes: «No hace falta estar arriba para ver lo que ya se sabe»; «Me tiro hacia arriba o me tiro hacia abajo»; "La luna y el bambú saben que estáis dentro de la piedra», añadiendo enigmáticas reflexiones: «No es el pódium de los onanistas. Es el escalonado de la crítica».

En definitiva, un conjunto armónico que nos hubiera gustado ver en forma de pequeño opúsculo o libro, pues se concibió así para ello, aunque finalmente, al igual que en otros ejemplos, no pudiera materializarse.
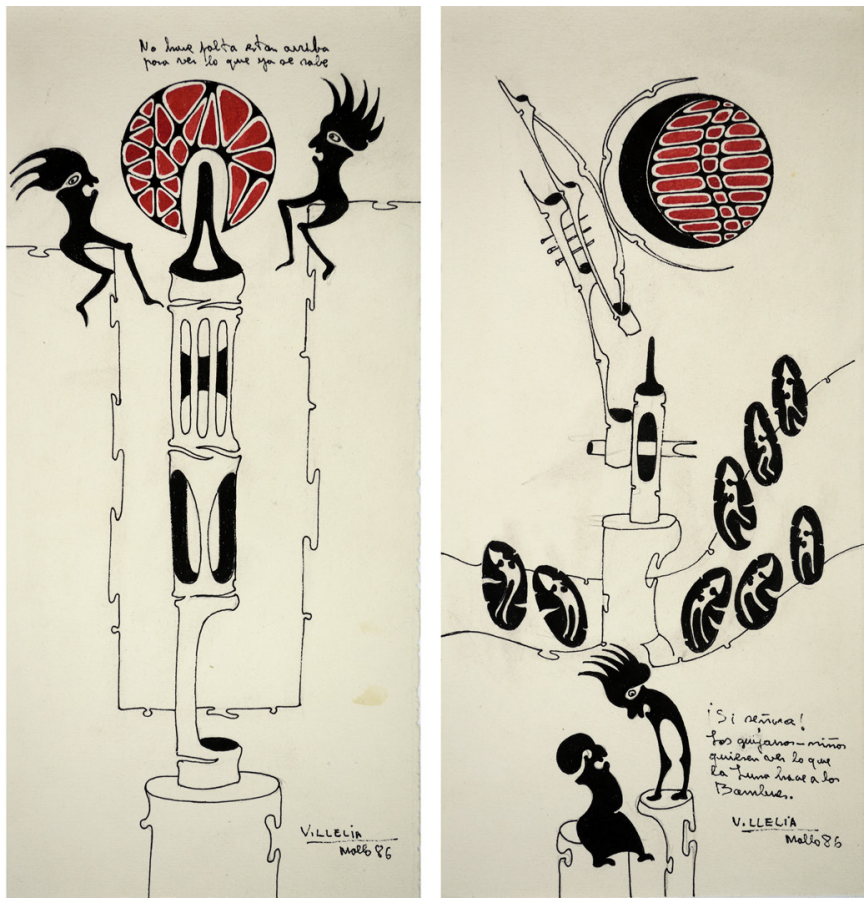

Por su identidad formal hemos citado seguidos los dos proyectos anteriores, a pesar de su diferencia temporal. Ahora hemos de regresar a los años setenta para retomar otra sugerente propuesta. Fisuras en el espejo [9] recupera el esquema de imágenes precedidas por un texto poético. Son nada menos que 100 láminas de $27 \times 20,5$ cm, trabajadas con tinta y acrílico en Molló durante 1972. El lenguaje plástico es abstracto, a partir de líneas fluidas y círculos de color, aunque parezcan percibirse evocaciones astrales o vegetales, a modo de hojas dentadas o brotes de bambú.

Una detenida observación permite adivinar subgrupos internos. En los primeros ejemplos las sucesiones de círculos siguen un patrón, con dominantes verticales $u$ horizontales. A partir de ahí surgen anillos abiertos de tonos cálidos que abarcan las proyecciones lineales o dialogan con ellas. $Y$ les siguen discos únicos completos que aumentan su tamaño hasta superar los bordes. La mancha así afirma su presencia y desarrolla un cromatismo que explora con libertad todas las posibilidades compositivas que ofrece la página.

El libro incluye un poema final que le da título y reproducimos en la imagen. La figura del dibujante esgrafiando detrás del azogue parece una evocación borgeana, en sintonía con «Los espejos» o la quinta estrofa de «Arte poética», 

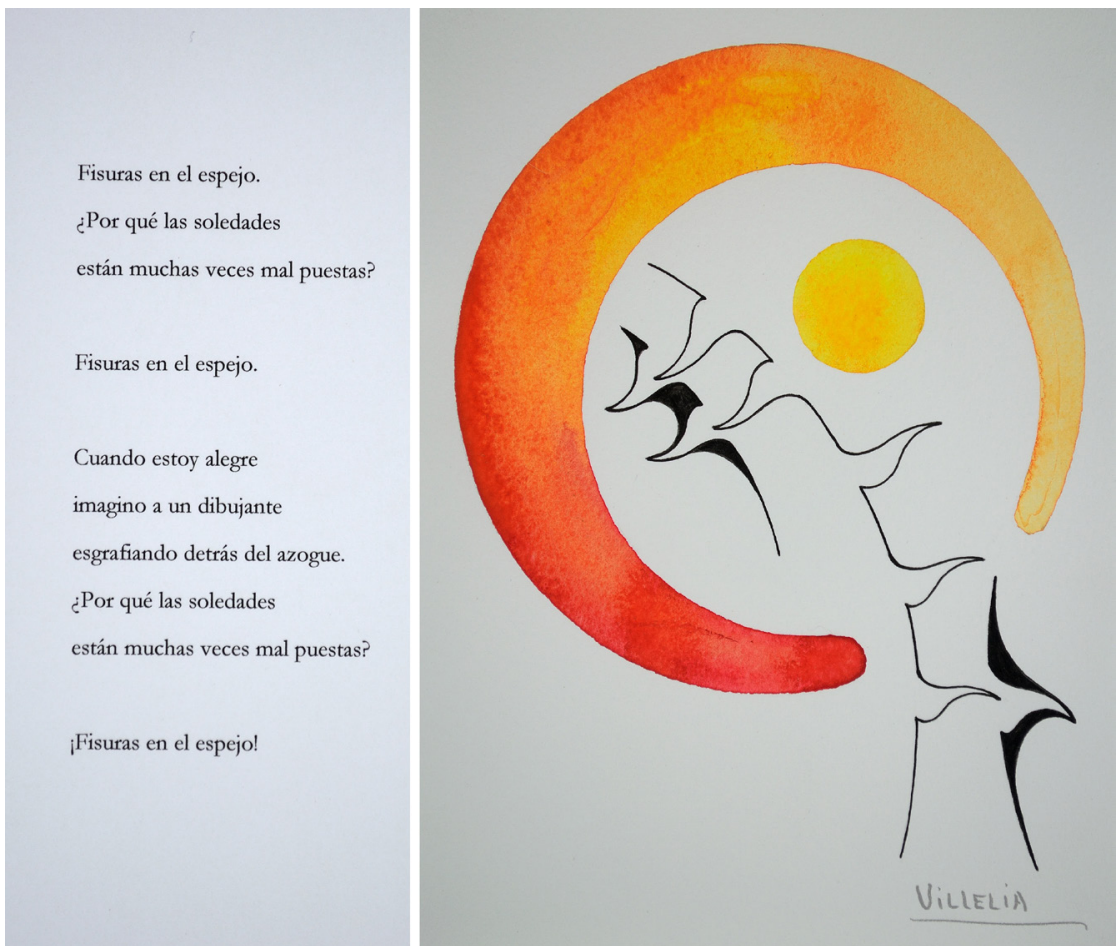

9. Fisuras en el espejo. Molló, 1972 publicados en El hacedor (Borges, 1960). Pero va precedido por otro texto, subdividido en 16 páginas, especialmente rico en sugerencias. Mezcla notas ecologistas, alusivas al deshielo, el cambio climático y la conservación de los bosques, con otras reflexiones relacionadas con la comunicación y el propio ejercicio de la escritura, para terminar con nuevas opciones surrealistas alusivas al paso del tiempo. No podemos reproducirlo completo, pero algunos versos dan idea de su riqueza y complejidad:

Todo sucedió simultáneamente.

Los dioses se cansaron de ser letras.

Las letras de ser signos verdaderos.

Los bosques presentían el asesinato y

la música especulaba con un tiempo

que precisamente no le pertenecía.

Empezaron a salir fisuras en el espejo.

...no obstante era preciso ordenar los poemas.
El espacio disponible nos condiciona a elegir un último ejemplo. La unidad de los conjuntos [10] fue creado en Molló durante 1973. Consta de 20 láminas de $11 \times 23 \mathrm{~cm}$, con un formato muy apaisado para facilitar su desarrollo. Como en otros libros recogidos, aquí también sorprende el punto de partida y los elementos que confluyen para despertar la idea. El texto introductorio comienza con unos versos de Rafael Alberti, uno de sus poetas predilectos y al que tuvo acceso a través de las ediciones que su hermano le enviaba desde Argentina: «Decidme de una vez si no fue alegre todo aquello. $5 \times 5$ entonces no eran todavía $25 \ldots{ }^{6}$. A la cita añade el recuerdo de un compañero del servicio militar, que se esforzaba por aprender las cuatro reglas matemáticas para poder ser cabo segundo en el ejército e intentar ingresar en la Guardia Civil; y señala: "Ataulfo sonreía al confrontar que 5 fusiles más otros 5 fusiles eran 10, al igual que los dedos de sus dos manos".

A partir de esta ingenua anécdota e imbuido por el tono surrealista del poema albertiano, Villèlia desarrolla un cúmulo de elucubraciones matemáticas, llamativas por la combinación de elementos numéricos, sígnicos y figurativos. Técnicamente alterna dibujos originales con otros hechos 
por él mismo en plantillas, mientras los números y símbolos proceden del sistema de transferencia Letraset, utilizado entonces por arquitectos y diseñadores gráficos. Usando el negro, el azul y el rojo, aglutina rayas, flechas, llaves, aspas, asteriscos, estrellas, interrogaciones... en un proceso creativo que parece inagotable.

Las asociaciones son tan sugerentes que permitirían elaborar enunciados al estilo de Joan Brossa: un gato equivale a 7 porque tiene 7 vidas; dos suman 14 y si le restas 13, queda un ratón. Animales reconocibles (conejos, ratones, gallos, perros, gatos, caracoles, ranas, pájaros) protagonizan la mayoría de las operaciones, pero hay que añadir la presencia de motivos extraídos de la cultura Quitu-Cara. En 1972 Moisès Villèlia concluía su estudio sobre esta civilización ecuatoriana vigente entre el 500 a. C. y el 500 d. C. ${ }^{7}$ Analizó en concreto los sellos planos (pirus) o cilíndricos (pikenus), que incluían por ejemplo manos con espirales, un estilizado mono o un sintético jaguar, cuya traslación casi literal apreciamos en las láminas. Este último, multiplicado y en vertical, como se hacía con los propios sellos ${ }^{8}$, propiciaba juegos compositivos modulares que remitirían al mejor Escher.

El resultado es ingenioso y cabe añadirle también un componente lúdico. Hay que imaginar al autor experimentando y disfrutando al descubrir cada nueva opción. Como otras iniciativas quedaría en un proyecto que no llegaría a verse impreso. $Y$ es que estos libros de artista no tenían una salida fácil, pero se revelan como un medio creativo eficaz y satisfactorio para el autor.

En conclusión, Villèlia es un artista de enorme personalidad, que aportó un nuevo material (la caña de bambú) al panorama de la escultura contemporánea, con un estilo propio e incomparable. Pero, aun siendo la escultórica su faceta más conocida, sus inquietudes no se limitaron al mundo tridimensional. La necesidad expresiva de Villèlia iba más allá y desde sus inicios utilizó también la literatura y el dibujo. La fusión de ambos recursos generó múltiples proyectos de libros de artista que son poco conocidos. Ante el convencimiento de que no se debe acometer de forma aislada la aportación de un artista tan multiforme, este trabajo contribuye a enriquecer su universo creativo.

Tras este recorrido descubrimos que, lejos de ser una actividad episódica, estos proyectos se mantienen a lo largo de su carrera a pesar de no tener una fácil salida. Los ejemplos seleccionados evidencian la continua vocación experimental
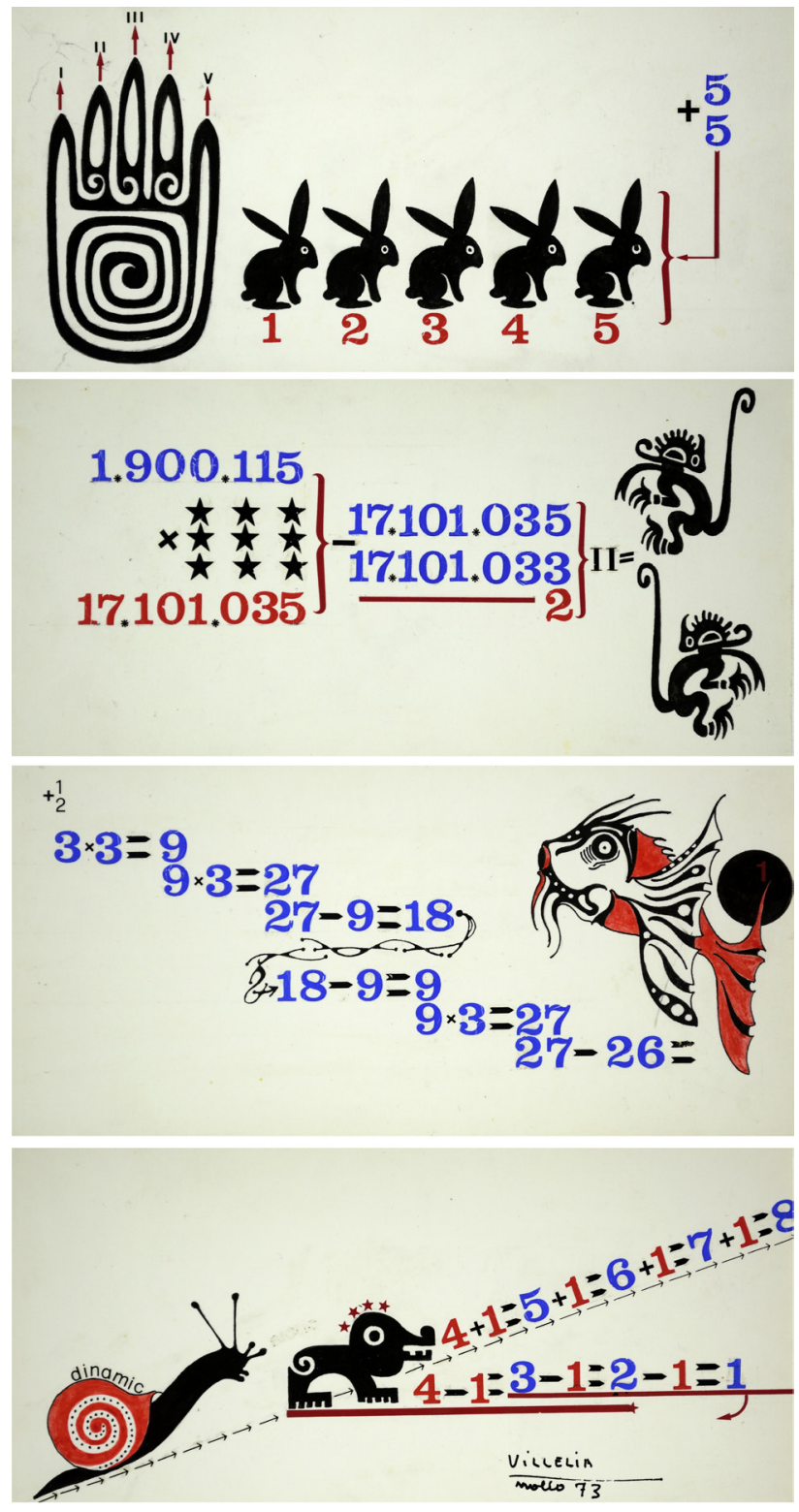

10. La unidad de los conjuntos. Molló, 1973

de Villèlia, pues al texto y la imagen suma perforaciones, números, signos y distintos lenguajes plásticos, que abarcan de la figuración surrealista a la pura abstracción. Al tiempo, los mecanismos inspiradores son muy diversos y recogen la convivencia cotidiana, relatos de otros autores, culturas indígenas y mundos generados por su propia imaginación, con un alto componente surreal. Lo aquí ofrecido es un buen testimonio, pero aún quedan aportaciones por recuperar. 


\section{Notas}

* Este texto ha contado con la Ayuda GR18101 del Fondo Europeo de Desarrollo Regional y la Junta de Extremadura (Consejería de Economía, Ciencia y Agenda Digital) al Grupo Investigador del SECTI «Arte y Patrimonio Moderno y Contemporáneo (HUM 012)».

1 De la recepción crítica de su obra da cuenta la selección de textos incluida en la página web del artista. <https://www.villelia.com/> (fecha de consulta: 1701-2021). La bibliografía del catálogo de la exposición antológica de 1999 en el IVAM recogía ya 187 referencias.

2 Su esposa, la artista Magda Bolumar, también se especializaría en el uso de este material. Su aportación plástica está siendo objeto de revisión (Lucas y Alario, 2019), con una también completa página web: <http://www.magdabolumarcherto.es/>.

3 Ferrant y Villèlia se admiraban mutuamente e intercambiaron elogiosos textos.

4 Agradecemos a Nahum Villèlia y su familia la información y facilidades ofrecidas para acometer este artículo. Su labor para difundir el legado de su padre ha sido encomiable, manteniendo durante años una página Web ya citada y ahora co-gestionada por la Galería Marc Domènech. En la última actualización de 2019 se ha incorporado a la misma una importante colección de dibujos.

5 Aportación del autor, bajo el título "Los personajes de Les Lilas y Los cromosomas, dos proyectos de libros de artista de Moisès Villèlia", al / Congreso Internacional de Arte y Literatura Diálogos en torno al libro: texto e imagen, organizado en Albacete por la Universidad de Castilla-La Mancha en octubre de 2020. La publicación derivada del mismo se encuentra en prensa.

6 Es el inicio del poema «En el día de su muerte a mano armada», de 1929, que conocemos por la recopilación posterior de la editorial Cátedra (Alberti, 1989).

7 Los resultados no fueron difundidos hasta 1992, y se recuperaron en una exposición de 2006 cuyo catálogo recoge los textos escritos por el matrimonio y una arqueóloga (Villèlia, Bolumar y Costales, 2006).

8 A través del análisis de unos 200 sellos, entre los que destacan los del yacimiento de La Tolita, fue el propio Villèlia quien descubrió el mecanismo de uso de los pikenus, cuyos esgrafiados suponen una octava parte de la composición total, trazando 4 recorridos en direcciones opuestas.

\section{Bibliografía}

ALBERTI, Rafael (1989), Sobre los ángeles. Yo era un tonto y lo que he visto me ha hecho dos tontos, Cátedra, Madrid.

BORGES, Jorge Luis (1960), «Arte poética» y «Los espejos», en El hacedor, Emecé Editores, Buenos Aires.

BORRÀS, Maria Lluïsa (1974), Villèlia, Polígrafa, Barcelona.

BORRÀS, Maria Lluïsa (1999), «El primer Villèlia» y VILLĖLIA, Nahum (1999), «Los libros. Lo poético y lo plástico, dos mundos que se entrecruzan», en Moisès Villèlia, IVAM Centre Julio González, Valencia, pp. 107-113.

CAMPS, Eudald (2005), «Villèlia o el somni de la materia» y VILLÈLIA, Nahum (2005), «Un artista, un material, un món», en Moisès Villèlia, Fundació Caixa de Girona, Girona, pp. 7-16.

CASTILLO, Alberto del (1974), «Crónica de Barcelona», Goya, n. 119, pp. 312-318.

CIRICI PELLICER, Alexandre (1982), «Villèlia o el azar con la necesidad», en Villèlia. Esculturas, Museo de Bilbao, Bilbao, pp. 5-6.

CORREDOR-MATHEOS, Josep (2005), «El solitario camino de Moisés Villèlia» y BUFILL, Juan (2005), «Bambú: la levedad, lo natural, el modo propio", en Moisès Villèlia y la articulación del vacío, Oriol Galeria d'Art, Barcelona, pp. 7-17.

GIL GREGORIO, Joan (2011), «L'escultura aèria de Villèlia» y VILLĖLIA, Nahum (2011), "Una concepció, una creació», en Moisès Villèlia. Memòria, Pilar Riberaygua Galeria d'Art, Andorra la Vella, pp. 7-12.

GIRALT-MIRACLE, Daniel (1974), «Moisés Villèlia, arquitecto del bambú», Batik, n. 4, marzo, pp. 10-12.

GIRALT-MIRACLE, Daniel y BARÓ, Roser (1983), «Moisés Villèlia: la plenitut del buit» en Moisès Villèlia, Generalitat de Catalunya y Fundació Joan Miró, Barcelona.

GONZÁLEZ HERNANDO, Irene (2011), «El diluvio universal», Revista Digital de Iconografía Medieval, vol. III, n. 6, pp. 39-49.

LICHTENSTERN, Christa (1996), Monumento a Apollinaire, Siglo XXI Editores, México.

LUCAS PALACIOS, Laura y ALARIO TRIGUEROS, María Teresa (2019), «Tirar del hilo: la naturaleza y el tejido en la obra de Magda Bolumar y Moisès Villèlia», BSAA Arte, n. ${ }^{\circ} 85$, pp. 297-315.

SUBIRANA, Rosa María (1976), «Molló 1975-1976: mòbils i escultures», en Moisès Villèlia. Escultures. Dibuixos, Sala Gaspar, Barcelona, pp. 3-6.

VILLÈLIA, Moisès, BOLUMAR, Magda y COSTALES, Pilar (2006), Quitu-Cara, una cultura entre els dos hemisferis. Estudi de Moisès Villèlia dels segells pirus i pik, Fundació Caixa Girona, Girona. 